\title{
INSPIRING STUDENTS TO UNLEASH SIMPLE TECHNOLOGICAL TOOLS TO PROVIDE BETTER DATA ANALYSIS TO DECISION MAKERS
}

\author{
Steven J. Henderson, United States Military Academy, steven.henderson@usma.edu \\ Elizabeth W. Schott, United States Military Academy, elizabeth.schott@usma.edu
}

\begin{abstract}
In an era of technological advances, the proliferation of large-scale datasets is both an asset and a challenge for decision makers. In educating future decision makers and analysts, it is difficult to recreate this paradox in the classroom. First, student ability in managing large-scale, realistic datasets is lacking. Students self-assess as being comfortable with technology in general, but lack the skills required to handle large quantities of data. Second, it is difficult to adapt large-scale and sometimes problematic datasets encountered in practice to exercises suitable for undergraduates. We describe an approach to teaching decision-making with large-scale datasets that involves a problem-based learning model derived from the field experiences of our faculty who regularly deploy as United States Army operations research analysts. This process involves our faculty returning from assignments as analysts in Iraq and Afghanistan and immediately adapting realistic datasets to classroom problems the very next semester. The approach emphasizes creation of Simple Technological Tools (STT) which are automated tools students build using advanced features of standard office software. This approach has been very successful in focusing the skill development of our students, motivating learning, and promoting an element of realism in our teaching of data analysis to support decision-making.
\end{abstract}

Keywords: Decision Support Systems, VBA Coding, Automating Microsoft Office, Education and Large-scale Datasets

\section{INTRODUCTION}

Today's college students live in a connected society. Walk across any college campus and you will see students emailing, texting, and checking social media sites. Studies have been done documenting the arrival of the "Net generation" or "Digital natives" to the college classroom [14] and their internet skills [4]. The arrival of these students however, has not necessarily correlated to improved digital literacy in general, and in fact students often overestimate their own abilities [4]. Additionally, other studies have found that in the "Google" generation, students rely heavily on such things as search engines rather than the original documents and thus are not developing the critical and analytical skills to assess the information that is so readily available on the web [12]. In light of this environment, our department has looked for ways to inspire this generation of students to unleash the power of technology to move beyond the simple review data and to create decision support tools that provide analysis and insights to both soldiers and leaders.

\section{Background}

In general, cadets entering the United States Military Academy (USMA) share the typical characteristics of all students entering undergraduate educational program. The students grew up in a technologically advanced era where and share common attitudes towards digital literacy and learning as the typical high school graduate. The students are however unique in many ways. First, all cadets are required to have the same equipment - which for instructors translates into computer systems that are configured and operate the same way. Second, all cadets are required to take a large selection of "core" courses, grounding them in a broad liberal arts education regardless of their major. Finally, all cadets share common career glide path, one in which graduation will result in a commission in the United States Army as a Second Lieutenants.

Likewise, while the academic faculty at the academy shares many common traits with colleges and universities everywhere, but as a whole they are unique as well. The current faculty is made up of 30\% civilian, 55\% rotating military faculty, and $15 \%$ permanent military faculty. Civilian faculty members are subject matter experts in their fields and provide in depth knowledge and expertise in their field. Rotating and Permanent Military faculty follow a 


\section{Issues in Information Systems}

Volume 14, Issue 2, pp.319-328, 2013

different career path as depicted in Figure 1 below. Junior rotating faculty members are selected from the officer population based on expertise and interest in an academic area as well as proven success as a company grade officer. These officers have spent 5-7 years in the active duty Army leading soldiers on a daily basis, often in combat. After selection, these officer are sent to graduate school for a Master's Degree in an appropriate field, followed by an assignment as an instructor as USMA. After their assignment, these officers return to their more traditional Army careers.

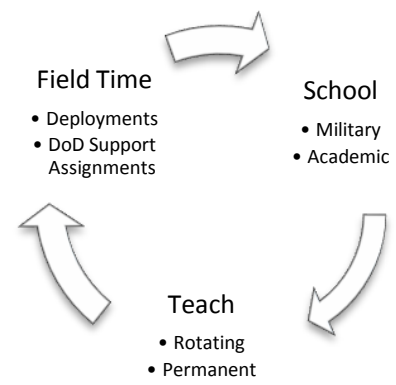

Figure 1: USMA Military Faculty Cycle

Senior rotating faculty follows a similar pattern. They are selected from active duty officers, sent back to graduate school for a $\mathrm{PhD}$, followed by an assignment as USMA. Most have been instructors before and all have had prior graduate level education. Permanent military faculty are additionally encouraged to routinely leave their current teaching assignment and return to the active-duty force in an effort to stay current or "re-green" on short duration deployments or sabbaticals. This assignment process affords the faculty valuable opportunities to both stay current with the on-going practices in the Army as well as share the latest research with their counterparts. Within the past five years, six of our nine permanent faculty members took advantage of these opportunities to deploy as Operations Research/ Systems Analysts (ORSAs) for six or twelve months in Iraq or Afghanistan.

\section{Problem-based Approach to Simple Technological Tools}

As our faculty members rotate through their field time and deployed sabbaticals, the department continually looks for ways to integrate their experiences into our courses. In doing so, faculty identified the need for our undergraduates to develop the analytical skills and experiences needed to analyze and manage large-scale datasets in support of operational decision making. Typical problem domains for deployed analysts include identifying trends in the enemy's use of improvised explosive devices (IEDs), identifying enemy IED networks, assessing the efficacy of military strategy and operations, and resource allocation. Solving problems in each of these domains involves the regular integration of data from multiple voluminous and disparate sources. Working with this data requires routine design, use, and maintenance of what we call Simple Technological Tools (STT )- relatively-small, single module, advanced, and custom software tools that analysts create using standard office software packages. In the case of the Army analyst, this mainly consists of software code modules written using Visual Basic for Application (VBA).

Instructors however found it challenging to directly integrate the deployed analyst problem scenarios and STT generation into our traditional, lecture-based undergraduate courses. While certain aspects of the deployed analyst experience could be isolated and scoped for homework problems and exams, it was difficult to replicate the analytical challenges faced when working with large-scale datasets. Additionally, the time required to expose students to the types of large-scale datasets faced by our recently deployed faculty was outside the confines of a typical course lecture. These challenges prompted us to examine a problem-based learning paradigm [2] as means to teach large-scale data management. The results of our efforts are described following a review of related works.

\section{Related Works}

The idea of problem-based learning (PBL) was pioneered by Howard Barrows and colleagues [2] as a means to improve the education of medical students. Originally termed practice-based learning, PBL presents students with challenging, real-world problems with little to no instruction and then inspires and motivates the students to selfdirect their own learning. As Savery and Duffey describe [15], there are no designated texts or lectures and the instructor takes on the role of consultant. Proposed goals of PBL include increased problem-solving abilities, team 


\section{Issues in Information Systems \\ Volume 14, Issue 2, pp.319-328, 2013}

collaboration, self-assessment, and the development of strategies to identify and collect new knowledge required to solve problems [15]. Although several studies have demonstrated contradictory evidence regarding its educational efficacy $[13,7]$ the PBL approach is generally credited with improving the motivation and intellectual inspiration of students. As described in Albanese and Mitchell's literature review [1], PBL strategies have since flourished in fields other than medicine, including significant application in the engineering disciplines. Woods [16] developed a PBL application at the sophomore and senior-design level in a chemical engineering program. Cawley [5] describes a PBL module used in a mechanical engineering curriculum. Hadgraft [9,10,11] implemented PBL courses in computing, civil engineering, and systems engineering.

Works most similar to ours include a high school-level PBL course designed by Fujioka and colleagues [8] that featured students programming toys with Visual Basic for Applications (VBA). A second similar work is a PBL course designed by Beaumont and colleagues [3] which tasked students to redesign a problematic database and accompanying user interface. Our department's approach differs from these and earlier works in that ours is the first work we know of that presents problems focused on large-scale datasets and is also tightly integrated with the very recent, real-world experiences of faculty members.

\section{APPROACH}

\section{Course Redesign to Support Challenge Based Learning}

To create our own problem-based learning paradigm to address large dataset education, the Systems Department looked at redesigning an existing course - Computer Aided Systems Engineering (SE370). This course is an integral part of the Systems Engineering, Operations Research, and Systems Management majors at our institution. It emphasizes the use of information technology in the Systems Decision Process, and exposes cadets to a range of software applications and illustrates how these applications support the Systems Decision Process. Cadets learn how to create, collect, manipulate, and analyze data in numerical and graphical forms to enhance problem solving, systems design, decision making, and engineering management processes.

In assessing the course, the program director looked to Bloom's Digital Taxonomy [6] as it relates to scaled lower to higher order thinking skills as shown in Figure 2 below. Although students today enter the course with a greater basic understanding of computers and technology, they still struggle with the high order thinking skills. These skills include the ability to not just review data but to also learn to analysis that data and provide useful tolls and insights to decision makers.

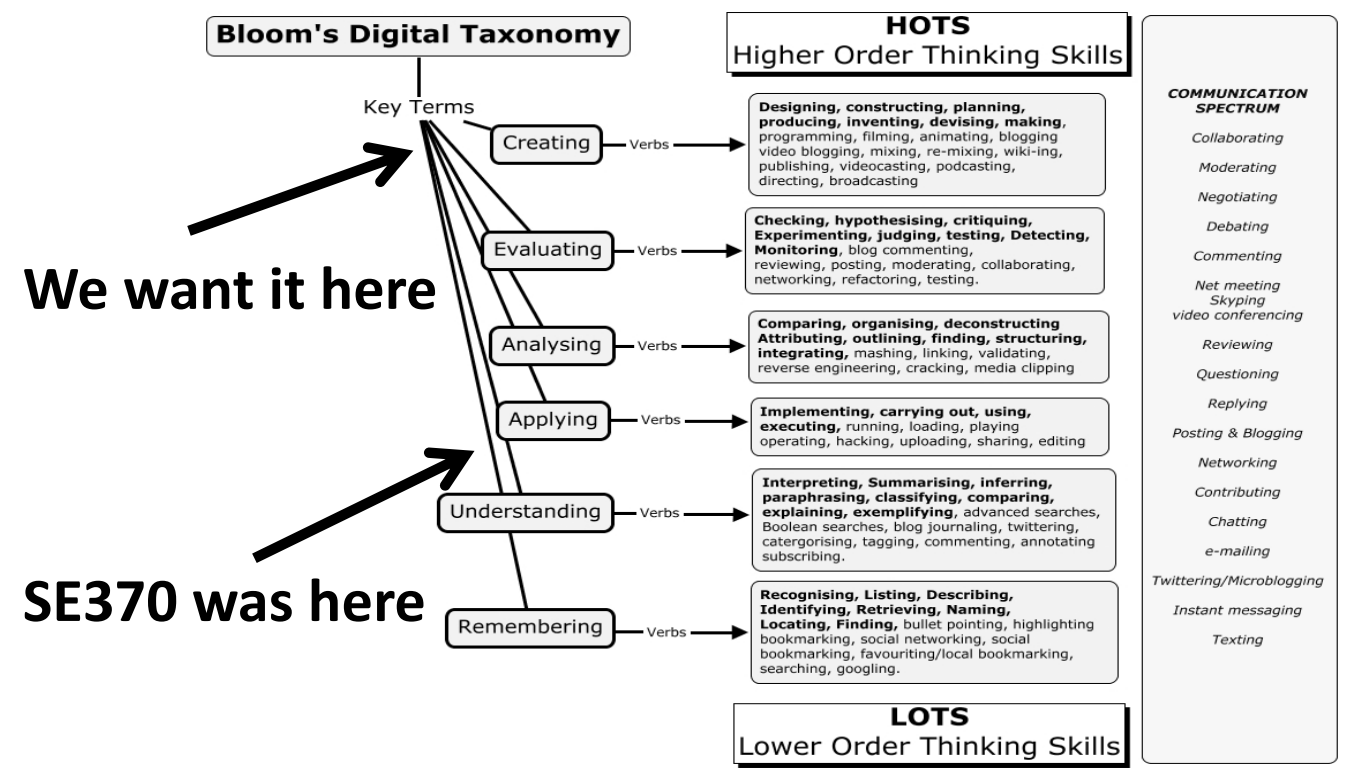

Figure 2: SE370 Course Assessment Situated Using Churches' “Bloom’s Digital Taxonomy” [6] 


\section{Issues in Information Systems}

Volume 14, Issue 2, pp.319-328, 2013

It is the department's challenge to move these students from basic data analysis to the level of digital literacy where they can actually create and automate tools (in our case, STTs) in a very limited amount of time. With our unique situation of all our gradates entering service into the Army and knowing they will have Microsoft Office and VBA tools at their fingertips, the course focused on starting with these.

\section{Course Methodology}

The course was reorganized around sets of progressive deliverables packaged in problems presented as hypothetical scenarios. Over the course of the semester, four scenarios which could be directly tied to their future service as Army Officer were used to drive the deliverables. Figure 3 below depicts the scenario-based course layout. A brief explanation of the possible course scenarios and sample deliverables are shown in Appendix A. These deliverables determined the schedule and learning objectives for the course. This model superseded the traditional "Lesson" model where lesson objectives were laid out and presented on a regular lecture schedule. In the place of providing lectures, the course provided the cadets dedicated lab time and resources to facilitate their own self-directed learning. These resources included a course text and an extensive set of external references such as whitepapers, how-to articles, and video tutorials. Instead of devoting class time to teaching low-level computer skills, instructors created their own short, three minute or less video tutorials. These tutorials were bundled with other resources and provided to students at the start of each deliverable.

SE370 Challenge-based Learning

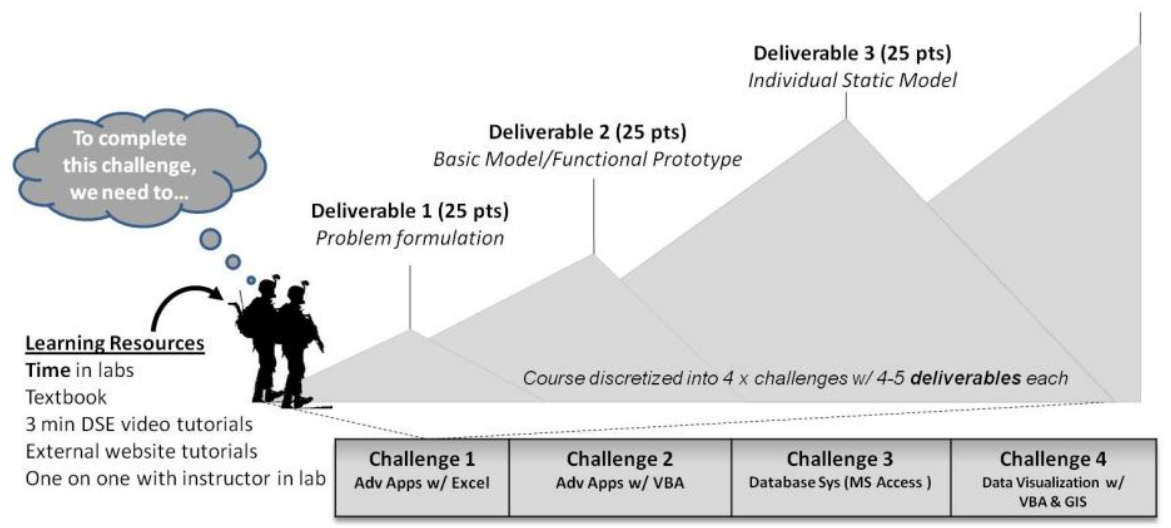

Figure 3: SE370 problem-based Learning Roadmap
Deliverable 4 (125 pts) Complete Dynamic System

Typical deliverables in the course required cadets (in teams of two) to upload their current design artifacts (e.g., macro-enabled spreadsheet, database, KML files, etc.) to include a narrated video screencast explaining how their artifact worked. Often times, the deliverables were defined as partially-completed works in progress having achieved only a certain level of functionality. We found partially-completed deliverables to be less cognitively disruptive to the student's learning momentum, and they also reduced the anxiety that is often associated with submitting graded events. Due dates for deliverables were only scheduled before certain class meetings, approximately twice per week. In these meetings, a few teams were picked at random to defend and demonstrate their artifacts in front of their peers. These presentations resembled collaborative brain-storming sessions with the entire class and instructor providing questions and feedback to the presenters. These sessions were a central part of the learning process as they served as principal motivation for the cadets to always be ready to present their work in class.

\section{Large-Scale Datasets as Problems}

A main ingredient of our problem-based approach involved exposing the students to large-scale datasets. For the course, the instructors define a large-scale dataset as a data source that is either voluminous in terms of the number of individual records (> 500,000 rows) and/or broad in terms of the number of disparate tables (> 15 disparate tables) that students have to coalesce. Appendix A lists specific details about the size and scope of the large-scale datasets encountered in this course. While this classification of large-scale datasets might pale in comparison to those encountered in the Big Data research community, instructors found their size posed three important challenges 


\section{Issues in Information Systems}

Volume 14, Issue 2, pp.319-328, 2013

for the students. First, the datasets employed were resilient to brute force analytical techniques such as the use of MS-Excel's built-in Pivot Tables or AutoSort feature. Instead, the students had to use VBA to automate these built-in functions and also create custom functions to perform the analysis required for each deliverable. Second, the large size of the datasets required the students to spend considerable time preprocessing the data to gain an understanding of the underlying scheme. Finally, the sheer size and complexity of the datasets provided a sense of realism that served as palpable motivation for the students.

\section{Simple Technological Tool Anatomy}

The STTs built by the students over the course of each scenario served as a second main ingredient of this problembased approach. Each of these STTs featured four components-a simple Graphical User Interface (GUI), a normalized backend dataset, a customized VBA code module, and one or more hidden helper datasheets. The goal of each STT is to provide a reconfigurable interface that an analysts or engineer can use to answer questions about the underlying data. The GUI built by each student in each STT provides this interface and abstracts out the large voluminous data in each scenario. The custom VBA code module contains the customized code the students write to manage the data in response to user interactions from the GUI. The hidden helper sheets provide ancillary data and lookup tables required to drive the GUI (i.e. drop-down box options) and store intermediate analytical results.

\section{DISCUSSION}

As of this writing, the department is currently finalizing the formal assessment of our latest iteration of SE370 executed this semester. However, preliminary assessment of our approach revealed three principal findings:

- Finding 1: This approach requires significant set up work to establish expurgated versions of realistic datasets

- Finding 2: Students express a hearty appreciation for the realism and large-scope of the challenges

- Finding 3: Students spend a significant amount of time outside class working on the challenge deliverables

Finding 1 stems from the requirement to port real-world datasets to expurgated versions suitable for release in a public institution. The datasets our recently-deployed faculty brought back from Afghanistan and Iraq were classified and required conversion to unclassified analogs. This conversion process involved creation of synthetic, yet realistic events such as IED attacks, personnel records, enemy small-arms engagements, battlefield damage assessment data, and weapons data. While not insurmountable, this process took significant time on part of our faculty. On the plus side, future iterations of the course will leverage much of this set up work. However, this finding is an important one when considering creation of a new problem-based learning model involving large-scale yet realistic datasets.

Finding 2 materialized in the form of verbal feedback received from our students. Although a formal, end of course survey is still pending, instructors received a plethora of anecdotal comments such as "I can really see how this course will help me in the Army" and "I feel like I can actually get a job after I graduate." We also observed several positive dynamics in the classroom that indicate the students appreciated the approach. Students regularly expressed interest in each others' work as indicated by them asking each other questions and offering assistance during presentation of deliverables. Students also developed a health spirit of competition on creation of their deliverables.

Finding 3 stems from a time study conducted over the course of the last academic year. Cadets were asked to record the amount of time spent outside of the classroom on a nightly basis. The data was averaged for each course and can be seen in Table 1. Over the course of the semester, instructors noticed the normal ebb and flow of time based on the due dates of the deliverables not only in this course but also in other competing courses. Still, the amount of time spent outside of the classroom was double that of most of the other courses within the department. Although final course survey and analysis are still being completed, hypotheses based on discussion with cadets varied. Instructor hypotheses include the challenge of changing from a breath to a depth course and the added level of challenge forced cadets to spend additional time, other felt that as the students were often in charge of their own learning the additional time came from the lack of experience at this level - undergrad students were not as efficient when learning on their own as when directed by instructors, and finally, many students where more motivated to 
explore and spend time of the projects when they were given the leeway to develop their own unique solutions to the challenges presented.

Table 1: Results of the AY13 time study

\begin{tabular}{|l|l|c|c|}
\hline Course & Course Title & $\begin{array}{l}\text { Credit } \\
\text { Hours }\end{array}$ & $\begin{array}{c}\text { Average student time outside of } \\
\text { class per lesson }\end{array}$ \\
\hline EM481 & Systems Simulation & 3.5 & 50.6 \\
\hline Capstone & Systems Design I and II & 3.5 & 45.5 \\
\hline SE485 & Combat Modeling & 3.5 & 28.7 \\
\hline SM484 & Systems Dynamics Simulation & 3.5 & 25.2 \\
\hline SE370 & Computer Aided Systems Engineering & 3.0 & 56.6 \\
\hline SE375 & Statistics for Engineers & 3.0 & 46.2 \\
\hline SE300 & introduction to Systems Engineering & 3.0 & 39.8 \\
\hline EM482 & Supply Chain Engineering and Information Management & 3.0 & 39.2 \\
\hline SE301 & Foundations of Engineering Design and Systems Management & 3.0 & 36.8 \\
\hline SM440 & Complex Systems Architecture & 3.0 & 34.0 \\
\hline EM384 & Analytical Methods for Engineering Management & 3.0 & 32.6 \\
\hline SE350 & Systems Modeling and design & 3.0 & 31.6 \\
\hline EM420 & Production Operation Management & 3.0 & 30.8 \\
\hline SE450 & Applied Systems Design and Decision making & 3.0 & 28.0 \\
\hline EM381 & Engineering Economy & 3.0 & 24.0 \\
\hline EM411 & Project Management & 3.0 & 23.2 \\
\hline SE387 & Deterministic Models & 3.0 & 21.4 \\
\hline SE385 & Decision Analysis & 3.0 & 17.5 \\
\hline SE388 & Stochastic Models & 3.0 & 12.3 \\
\hline & & & \\
\hline
\end{tabular}

\section{FUTURE WORK}

The Systems Department future efforts are focused on fully assessing the results of a problem-based approach, properly scoping future iteration of the course, and continuing to adapt the recent experiences of faculty as they continue to deploy to support active-duty Army missions. Immediate assessment efforts involve an ongoing courseend survey from our last iteration of SE370. This survey will provide qualitative feedback from the students and help us gauge how well we scoped the course and met course objectives. Longer-term assessment plans include assessing how the skills honed in SE370 materialize in the senior capstone design course and also comparing the effectiveness of the problem-based approach to other techniques used in similar courses. Instructors are also making efforts to better understand the drivers behind Finding 3, and properly scope future iterations of the course. Options for future iterations of the course include reducing the number of deliverables or excluding entire scenarios from the course as to allow more time in others. Future plans also include taking time to adapt the datasets used in the course to new experiences brought back by faculty who continue to deploy in support of ongoing Army missions. This includes updating synthetic datasets to reflect real-world counterparts and also defining entirely new datasets as deployed faculty find themselves working in different problem domains.

\section{CONCLUSIONS}

In this paper, we introduced our approach for improving the education of future decision-makers and analysts as it relates to the management and analysis of large-scale datasets. This approach is notable in that it combines the wellestablished problem-based learning paradigm with our unique faculty development cycle to create an engaging model for students to learn about realistic, large-scale datasets. This environment focuses on teaching students to design and use Simple Technological Tools to analyze data. While more work is required to fully assess the efficacy of our approach, initial findings indicate careful scoping of course deliverables is required to avoid taxing student time outside of class. Additionally, there are significant set up costs incurred in creating expurgated analogs of large-scale, real-world datasets. However, the motivation, inspiration, and classroom dynamics we've witnessed in students have encouraged us to continue pursuing and perfecting our approach.

\section{REFERENCES}

1. Albanese, M. A. \& Mitchell, S. (1993), Problem-based learning: A review of literature on its outcomes and implementation issues. Academic Medicine, 68, 52-81. 


\section{Issues in Information Systems}

Volume 14, Issue 2, pp.319-328, 2013

2. Barrows, H. S., \& Tamblyn, R. M. (1980). Problem-based learning: An approach to medical education (Vol. 1). Springer Publishing Company.

3. Beaumont, C., Owens, T., Barret-Baxendale, M. \& Norton, B. (2008). Blended problem-based learning for widening participation: a case study. Innovation in Teaching and Learning in Information and Computer Sciences, 7, 44-72.

4. Carlson, R.D., \& Repman, J. (2000). Experience speaks! What web instructors wish they'd known. WebNet Journal, 2 (1), 11-13.

5. Cawley, P. (1991). A problem-based module in mechanical engineering. The Challenge of Problem Based Learning, 177-185.

6. Chruches, . Blooms Digital taxonomy. http://edorigami.wikispaces.com. Jones C., Ramanau R., Cross S., and Healing G. (2010). Net generation or Digital Natives: Is there a distinct new generation entering university? Computers \& Education, 54,722-732.

7. Colliver, J. A. (2000). Effectiveness of problem-based learning curricula: research and theory. Academic Medicine, 75(3), 259-266.

8. Fujioka, T., Takada, H., \& Kita, H. (2006), What Does Squeak Provide Students with?---A Comparative Study of Squeak eToy and Excel VBA as Tools for Problem-Solving Learning in High School---. In The Fourth International Conference on Creating, Connecting and Collaborating through Computing (C5'06), pp. 42-49.

9. Hadgraft, R.G. (1991), Experiences of Two Problem-Oriented Courses in Civil Engineering, in the 3rd Annual Conference of the Australasian Association for Engineering Education. pp. 292-297.

10. Hadgraft, R. (1992), Problem-based learning-Making it work. in the 4th Annual Conference of the Australasian Association for Engineering Education, 134-139.

11. Hadgraf, R. (1997). Student reactions to problem-based fourth year computing elective in civil engineering. European Journal of Engineering Education, 22 (2), 115-123.

12. Rowlands, I., Nicholas, D. Williams, P., Huntington, P., Fieldhouse, M., Gunter, B., Withey, R., Jamali, H., Dobrowoiski, T., Tenoppir, C. (2008) The Google generation: the information behavior of the researcher of the future. Aslib Proceddings, Vol 60 Iss 4, 290-310.

13. Norman, G. R., \& Schmidt, H. G. (1992). The psychological basis of problem-based learning: a review of the evidence. Academic Medicine, 67(9), 557-65.

14. O'Hanlon, N. (2002). Net Knowledge: Performance of new college students on an Internet skills proficiency test. Internet and Higher Education 5, 55-66.

15. Savery, J. R., \& Duffy, T. M. (1995). Problem based learning: An instructional model and its constructivist framework. Educational Technology. Saddle Brook, NJ, 31.

16. Woods, D.R., (1997). Issues in implementation in an otherwise conventional programme. The Challenge of Problem Based Learning, $2^{\text {nd }}$ Ed. Kogan Page, London, 173-180.

\section{APPENDIX A: Sample Scenario and Deliverables}

\section{Scenario One: The Value of Retention}

You have arrived at your new unit three months after the unit has returned from combat. Your commander informs you that the unit is scheduled to deploy again in 12 months and his number one priority is retention. For some reason many of the Soldiers in the unit think they can get out of the Army and make a lot more money. Your commander wants you to build a tool that the officers in the unit can use when counseling their subordinates. The main purpose of this tool is to determine the monetary value of a Soldiers service to the 20 year mark. Things to consider: Guaranteed salary, Tax free Housing allowance, Tax free special pays, GI Bill, Education allowance, Value of Health care, Value of retirement, Deployment Special Pays

Soldier Pay Deliverable 1: Submit a completed influence chart of the problem in Microsoft Visio and an Excel workbook that displays a Soldiers pay when rank and years of service are the input.

Soldier Pay Deliverable 2: Submit a completed Microsoft workbook that calculates the value of staying to retirement for one Soldier. This is a static model that clearly communicates information on a soldier of a rank and year of service of your choosing.

Soldier Pay Deliverable 3: Submit a completed Microsoft workbook that calculates the value of staying to retirement for any Soldier. This is a dynamic model that accepts input and dynamically updates, clearly 


\section{Issues in Information Systems}

Volume 14, Issue 2, pp.319-328, 2013

communicating information based on the inputted Soldiers information. Submit a screen cast (not to exceed 3 minutes in length), with commentary, that demonstrates: Demo, Design, Strengths and Weaknesses, Suggested Future Work and Documentation.

Dataset Description: This scenario involved students combining the following disparate datasets: The DoD pay tables, the DoD Housing allowance tables for all zip codes, the IRS tax tables, and the US Department of Labor database of civilian careers.

\section{Example STT:}

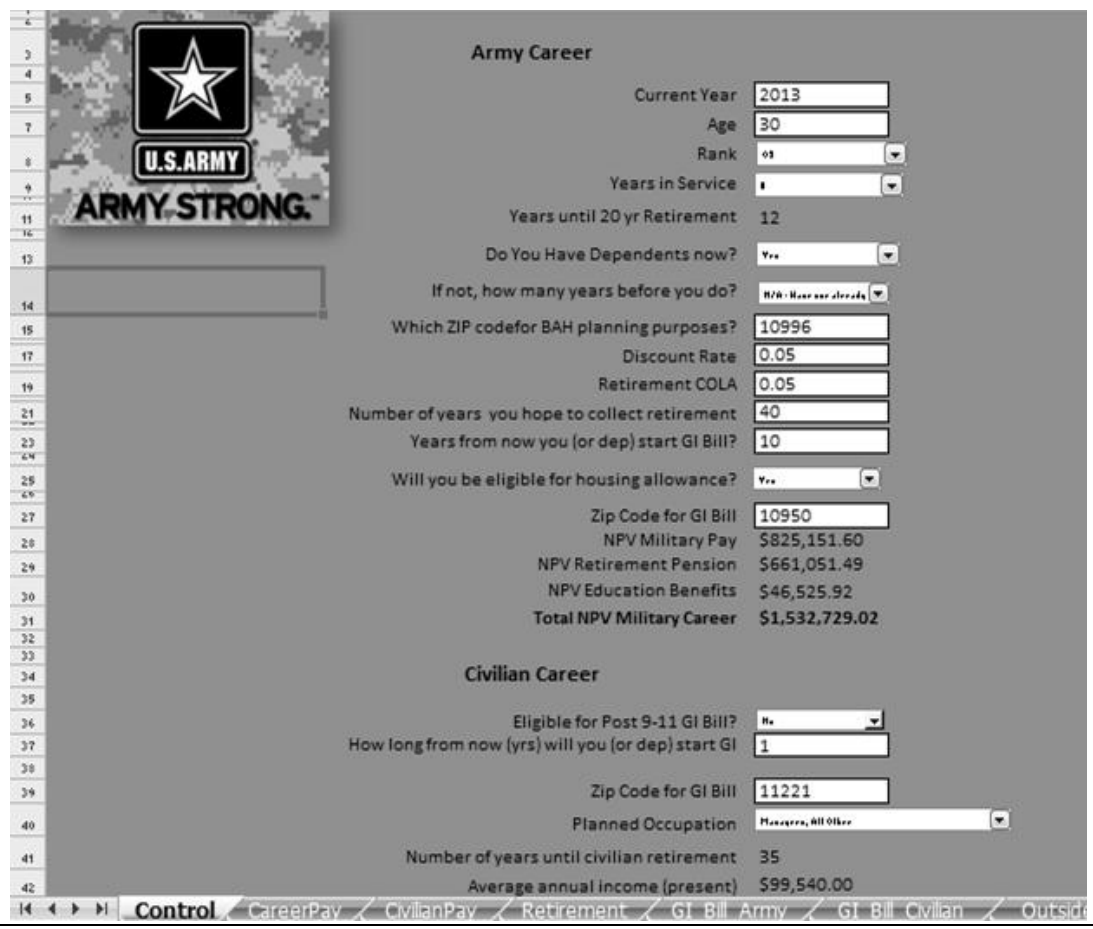

\section{Scenario Two: Company Database}

You have just arrived at your first unit, Alpha Company of 1st Battalion 15th Infantry Regiment, 3rd Brigade Combat Team. You soon realize that in addition to their Platoon Leader jobs all the other Lieutenants are often working intently on a variety of additional duties. The Company Commander, Captain Kennedy appoints you as the Training Room Officer. He states that the Company has been struggling to manage all the reports that area required to be submitted routinely. The Captain Kennedy instructs you to fix the problem and report back on your progress in one month. The next morning you sit down with the Training Sergeant and he proceeds to lay out the situation. He rattles off at least ten tracking documents that require updating on a daily basis, all of which have different formats. Sergeant Jones further describes the reoccurring situation of higher headquarters requesting very specific information that requires him to spend hours cross referencing different spreadsheets. The clerks in each of these shops (S1, S2, etc.) show you numerous examples of their reporting requirements and describe how often the format changes without warning. The most immediate problem you have identified is that the use of separate spreadsheets to store data which often contain some of the same information, albeit in different formats, is highly inefficient. To make matters worse, the documents are not held on a share drive and different versions are simply emailed back and forth. This has created situations where parties are wasting time updating older versions. You think back to your SE370 experience and realize that Microsoft Access is the perfect to tool to begin to sort out this problem.

Database Deliverable 1: Entity Relationship Diagram

Database Deliverable 2: Database backend in $3^{\text {rd }}$ Normal Form

Database Deliverable 3: Database frontend allowing for a leader to look across the personnel, training, and equipment in an Army Battalion. 


\section{Issues in Information Systems \\ Volume 14, Issue 2, pp.319-328, 2013}

Dataset Description: This scenario involved students combining the following disparate datasets: Personnel data for a hypothetical battalion of 500 personnel and their dependents, training records for these 500 personnel $\times 80$ training events, and equipment assigned to the personnel.

Example STT:

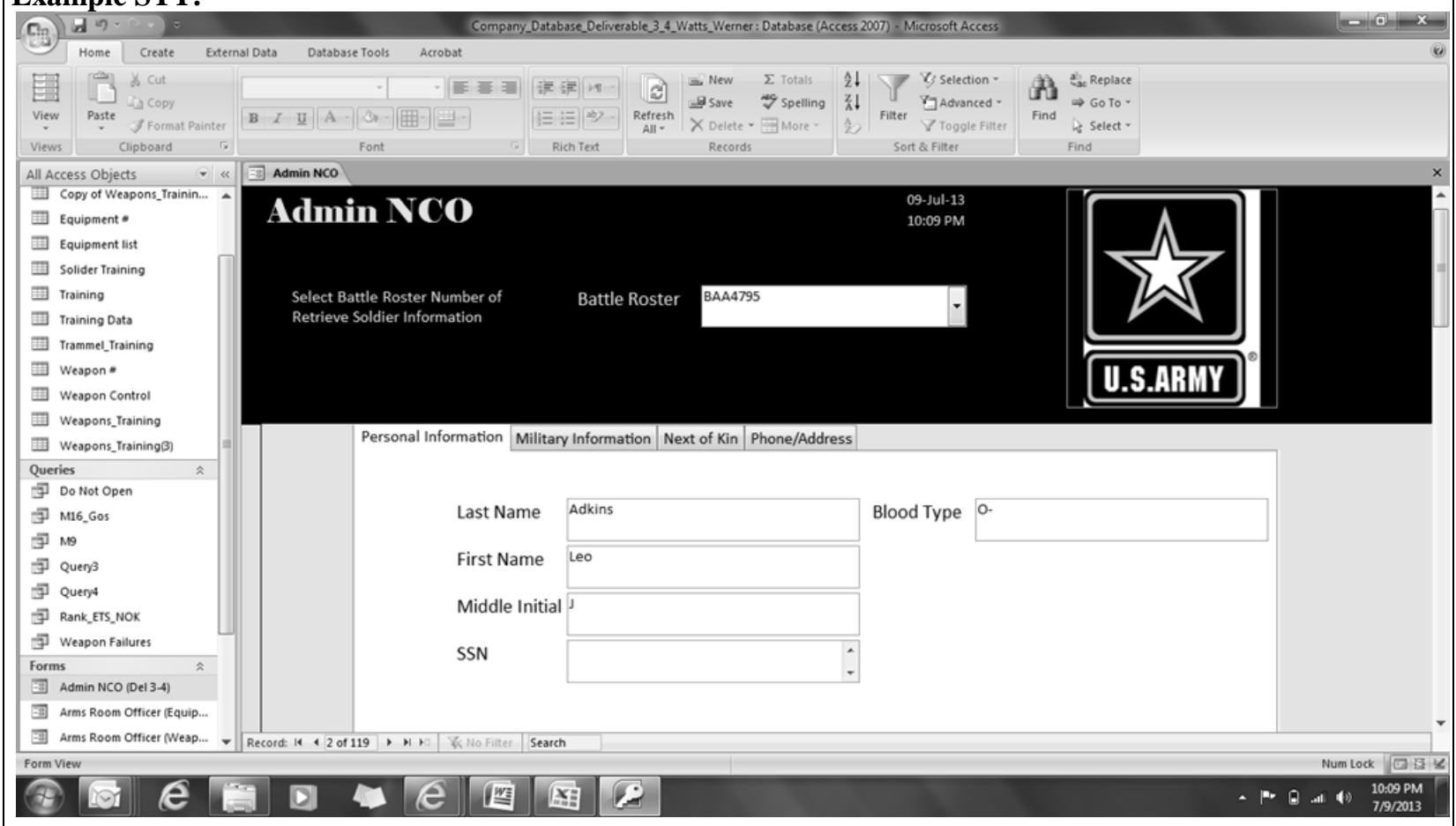




\section{Issues in Information Systems \\ Volume 14, Issue 2, pp.319-328, 2013}

Scenario Three: Arigon IED Dashboard

You recently reported to your first duty assignment with the 71st Ordnance Group (EOD) also known as TASK FORCE (TF) RAPTOR. Soon after your arrival, TF RAPTOR deployed in support of OPERATION ALLIED HOPE, a NATO-backed counter-insurgency (COIN) operation in the country of Arigon. Your Group Commander places you in charge of the TF RAPTOR Operations Research and Systems Analysis (ORSA) Cell with-in the S2 section. A major aspect of your mission within the country of Arigon is analyzing the threat of Improvised Explosive Devices (IEDs). Figure 4 shows a plot of all IED-related Significant Activity (SIGACTS) for a one month period. As the TF ORSA, your job will involve reviewing data from similar SIGACTS to determine how, where, and why insurgents are employing IEDs. As you assume your new duty position, you realize you can save your shop a lot of work by automating some of your recurring analysis. Most of this analysis centers on a weekly IED Statistics report that features dozens of charts and tables summarizing and categorizing IED attacks. Currently, your shop spends hours putting this report together from scratch and most of the work is copying, pasting, and reformatting the same type of information week after week.

Figure 4: Arigon IED Activity (Nov-Dec 2012)

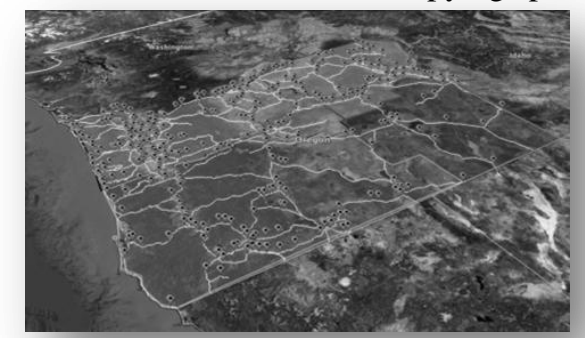

Arigon Deliverable 1: Recorded Macro Analysis

Open the Arigon_IED_Deliverable_1.xlsm Macro enabled Excel worksheet. Add a VBA comment (Use the symbol above the tab key) before each line in the subroutine describing what was the purpose of that line.

Arigon Deliverable 2: 3rd Party Macro Reuse

Use a supplied $3^{\text {rd }}$-party macro to divide a large set of IED data into separate worksheets for each of the Multinational Division (MND) sectors in Arigon.

Arigon Deliverable 3: IED Dashboard

Construct on interactive dashboard that allows an analyst to explore IED attacks and vehicle damages for any period of time. Provide filters for unit type, switch type, and mission.

Dataset Description: The Arigon dataset features and IED table containing $800 \mathrm{~K}$ records $\times 40$ fields each for each IED in the fictional country. Additionally, there are $80 \mathrm{~K}$ vehicle damage records that correspond to vehicles damaged by each IED strike.

Example STT:

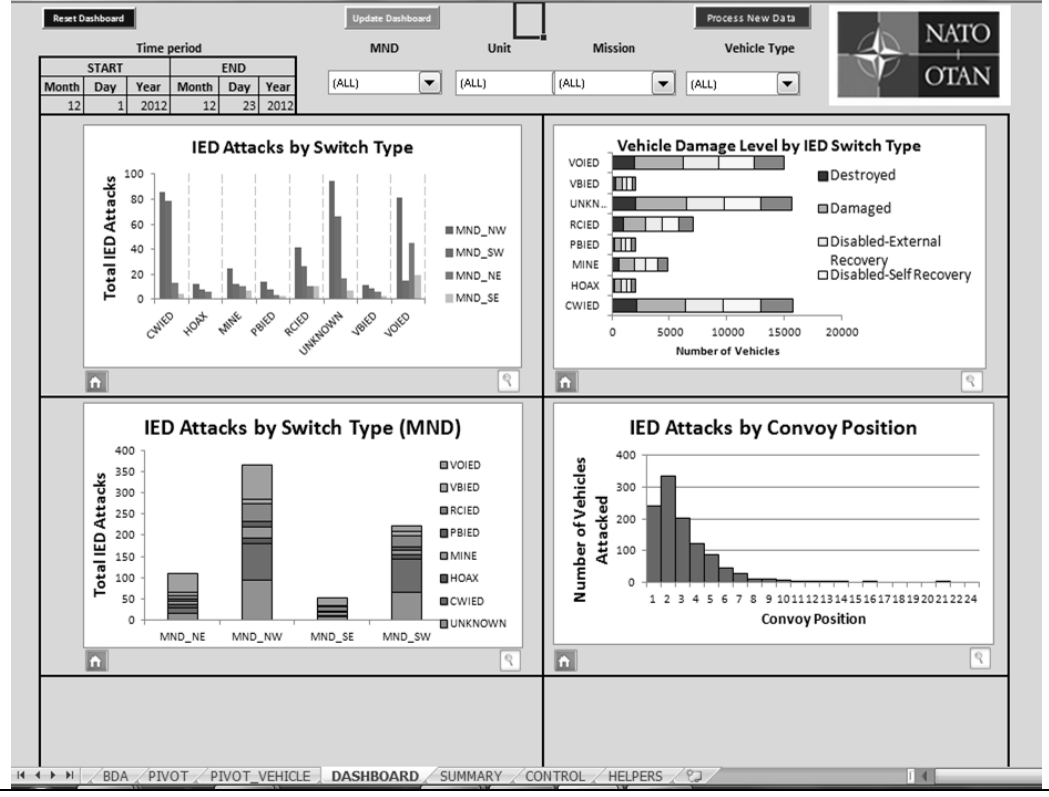

